\title{
ESCREVENDO UM ROMANCE, PRIMEIRO CAPÍTULO: PRECEDENTES E PROCESSO DECISÓRIO NO STF ${ }^{1}$
}

\author{
Adriana de Moraes Vojvodic, Ana Mara França Machado, Evorah Lusci Costa Cardoso
}

WRITING A NOVEL, CHAPTER ONE: PRECEDENTS AND DECISION

RESUMO

O ARTIGO, POR MEIO DO ESTUDO DE CASOS EXEMPLIFICATIVOS,

PROCURA MOSTRAR QUE UM DOS MOTIVOS PARA A FALTA DE UMA

CULTURA DE RESPEITO AOS PRECEDENTES JUDICIAIS NO SUPREMO

Tribunal Federal (STF), ou PARA A FALTA DE UM ROMANCE EM

CADEIA (DWORKIN), É A DIFICULDADE DE FORMAÇÃO DE UMA RATIO

DECIDENDI COMUM ENTRE OS MINISTROS NOS JULGAMENTOS DA

CORTE, EM VIRTUDE, POR EXEMPLO, DO PRÓPRIO PROCESSO

DECISÓRIO DO TRIBUNAL. A FALTA DE PADRÕES DE DECISÃO IMPLICA

QUE CADA CASO SEJA DECIDIDO SEM REFERÊNCIA A CASOS

PREVIAMENTE RELACIONADOS. ESSE CONTEXTO PODE COLABORAR

PARA A FALTA DE TRANSPARÊNCIA DECISÓRIA E PARA O QUE PODE

SER CONSIDERADO UM DEFICIT DEMOCRÁTICO DO STF.

PALAVRAS-CHAVE

STF; PRECEDENTES; PROCESSO DECISÓRIO; INTERPRETAÇÃO; ROMANCE EM CADEIA.

\author{
ABSTRACT \\ THROUGH THE ANALYSES OF LANDMARK CASES, THIS ARTICLE \\ ARGUES THAT ONE REASON FOR THE TENDENCY BY THE \\ BRAZILIAN SUPREME COURT (STF) TO DISREGARD JUDICIAL \\ PRECEDENTS IS THE DIFFICULTY TO CREATE A COMMON RATIO \\ DECIDENDI IN COURT DECISIONS AND PREVENT THE \\ EMERGENCE OF DWORKIN'S CHAIN OF LAW. THIS IS DUE, \\ IN PART, TO THE COURT'S OWN DECISION PROCESS. THE LACK \\ OF A DECISION PATTERN ENTAILS THAT EACH CASE IS DECIDED \\ WITHOUT REFERENCE TO PREVIOUS CASES. THIS CONTEXT \\ MIGHT FOSTER AN ATMOSPHERE IN WHICH DECISIONS ARE \\ NOT TRANSPARENT, SOMETHING WHICH RISKS CREATING A \\ DEMOCRATIC DEFICIT ON THE STF. \\ KEYWORDS \\ STF; PRECEDENTS; DECISION PROCESS; INTERPRETATION; \\ CHAIN OF LAW.
}

\section{INTRODUÇÃO}

O Supremo Tribunal Federal (STF) tem passado por profundas transformações nos últimos anos, por iniciativa, principalmente, de seus próprios ministros. Talvez o principal ponto de mudança esteja na busca pela redução da competência do Tribunal - ou seja, busca pela redução de casos de admissibilidade ou cabimento de recursos). Súmula vinculante e cláusula de repercussão geral, aprovadas pela Emenda Constitucional 45 de 2004, tentam eliminar do horizonte de trabalho dos ministros uma série de casos. Mesmo na própria jurisprudência do Tribunal é possível identificar iniciativas destes ministros para a extensão de efeitos de suas decisões para outros casos. 
É o que aconteceu com um habeas corpus em que o STF decidiu pela inconstitucionalidade de um trecho da lei sobre crimes hediondos. Por ser uma ação de controle difuso de constitucionalidade, a decisão deveria gerar efeitos apenas entre as partes. A Defensoria Pública da União, no entanto, defendeu na Rcl n. 4335 que a decisão proferida pelo STF era vinculante e que deveria valer também para outros casos. O ministro relator, Gilmar Mendes, adotou esse entendimento, conferindo efeito erga omnes à interpretação de inconstitucionalidade, ainda que não tenha sido feita em uma ação direta de inconstitucionalidade. O caso ainda não teve o pronunciamento de todos os ministros, mas, se a decisão do Tribunal atribuir o efeito erga omnes, alterará substancialmente a história do controle de constitucionalidade do Tribunal.

A preocupação dos ministros, no entanto, não parece ser meramente quantitativa - visando reduzir o número de casos decididos a cada ano -, mas também qualitativa. Em alguns deles, os ministros parecem buscar maiores efeitos às suas decisões, transformando-as em casos paradigmáticos, em precedentes. Certamente, essa não é uma iniciativa apenas dos ministros. Um caso paradigmático depende de uma conjunção de fatores, como mobilização social em torno do tema, cobertura da mídia, manifestações de parlamentares ou membros do Executivo, contrária ou favoravelmente. Tudo isso nos dá a impressão de que o STF tem se deparado cada vez mais com “casos difíceis” - interrupção da gestação de fetos anencéfalos, pesquisas com células-tronco, demarcação de terras indígenas, união homoafetiva, proibição de nepotismo - e conquistou um espaço diário e aparentemente definitivo nos jornais, tornando-se um ator político relevante.

Nesse cenário, verificamos a existência de dois usos das decisões do STF. Em casos repetitivos ou recorrentes, cuja matéria é menos complexa, como forma de controlar o volume de casos que chegam à sua alçada, as decisões proferidas pelo STF estariam funcionando como um mecanismo de filtro de decisões. Uma vez que cada um dos ministros tem de dar conta de um volume de distribuições individuais no ano que supera a casa dos dez mil feitos, ${ }^{2}$ essa parece ser a solução encontrada pela corte para dar vazão aos conflitos de sua pauta. É importante notar que, apesar do imenso volume de distribuições anuais, essa corte tem baixa taxa de congestão e consegue dar vazão, ano a ano, a quase totalidade de processos recebidos (VERÍSSIMO, 2008).

O outro uso que o STF está dando para suas decisões é visível em julgamentos relevantes de casos emblemáticos. Mais sensíveis devido à resolução mais complexa e ao acompanhamento da mídia, eles exigem, por parte dos ministros, maior carga de argumentação. Nesses casos, verificamos a preocupação, por parte dos ministros, em formar um entendimento sobre o litígio que sirva como precedente para casos posteriores. Esse posicionamento nos leva a crer que as duas funções dadas por suas decisões seguem o caminho de aproximação do STF ao papel de um tribunal constitucional, um modelo distinto de outras cortes constitucionais, mas que se apega a 
algumas das características comumente atribuídas a essas cortes. Esse modelo diferenciado já foi denominado corte constitucional "à brasileira” (VERÍSSIMO, 2008).

Este artigo tem por objetivo analisar a formação de precedentes desse segundo tipo de decisão.

Os casos recentes supracitados ilustram um "ativismo" maior do Tribunal, tanto no que se refere à maior interferência da decisão do STF no texto da lei interpretada, quanto à repercussão que essas decisões têm na mídia e nas instâncias judiciais inferiores.

Três casos recentes decididos pelo STF podem ser encarados de modo a compreender melhor essa nova postura do Tribunal quanto a suas decisões e formação de precedentes. O primeiro caso que pode ser aqui mencionado é a recente decisão do STF na ação que questionava a constitucionalidade da permissão de pesquisas com células-tronco embrionárias, prevista na Lei de Biossegurança (trata-se da ADI n. 3510). A inquestionável atenção dada ao caso, tanto pelas comunidades jurídica e médica, quanto pela própria mídia e sociedade civil organizada, foram responsáveis por uma grande mobilização do Tribunal para a solução final do caso. Os ministros não se limitaram a analisar a constitucionalidade da lei, tendo alguns deles apresentado condições à sua constitucionalidade, que envolviam ações externas do Executivo, como o monitoramento do uso das células-tronco e a criação de órgãos responsáveis pela fiscalização dessas pesquisas. A despeito de essas condições não comporem a decisão final da corte - que, por maioria, considerou integralmente constitucional o dispositivo -, pode-se entender que, ao incluírem essas condições, os ministros do STF teriam agido como "legisladores", pois essas inclusões demonstram um papel mais "ativo" que o esperado: a mera interpretação constitucional da lei e a declaração de constitucionalidade ou inconstitucionalidade, sem impor qualquer condição. ${ }^{3}$

Além dessa "interferência" no conteúdo da lei, a solução - que teve de se voltar à conceituação jurídica da vida e determinar alguns elementos de proteção a esse direito -, citada pelos próprios ministros do STF, já é uma etapa capacitadora do Tribunal para análise da constitucionalidade da interrupção de gravidez em caso de feto anencéfalo.

De fato, pouco tempo após a decisão da ação sobre pesquisa com células-tronco, em maio de 2008, o Tribunal voltou a colocar em pauta a discussão referente aos anencéfalos, possibilitando a manifestação da sociedade civil e de especialistas no assunto em audiências públicas. Percebe-se que um caso abre espaço político para a discussão de outro. A decisão sobre células-tronco possibilitou a retomada do tema de interrupção de gravidez de anencéfalo e, possivelmente, no futuro, para a discussão sobre aborto em geral.

Outro caso recente e muito debatido entra como exemplo do uso que o STF tem dado às suas próprias decisões. Trata-se da decisão no caso Raposa Serra do Sol, que discutiu o tema da demarcação de terra indígena e que atraiu muita atenção justamente pela possibilidade de o STF posicionar-se sobre o tema, gerando um precedente. 
Ele possibilitou ao STF definir o que entende por propriedade indígena, à luz da Constituição Federal de 1988.

Assim como no caso de pesquisa com células-tronco, os ministros colocaram condições ou ressalvas à "implementação" da interpretação constitucional sobre os elementos constitutivos da propriedade de comunidades tradicionais sobre a terra, sobre demarcação, no caso de terras indígenas. Um amplo debate sobre se o modo da demarcação deveria ser contínuo ou em "ilhas" ocupou os jornais, sendo que alguns ministros “anteciparam” seu posicionamento à imprensa, ao mesmo tempo em que testavam a aceitação de seus argumentos, tudo durante um julgamento diferido no tempo, com pedidos de vista e votos proferidos em períodos espaçados.

A polêmica que envolve a demarcação de terras indígenas não é recente, sequer para o STF - somente a disputa da Raposa Serra do Sol já dura mais de dez anos no Tribunal. Especificamente nesse caso, uma conjunção de fatores pode ter colaborado para a percepção de que a decisão poderia ser paradigmática. Impressiona particularmente a mobilização de vários atores em diferentes fóruns, com o objetivo de influenciar direta ou indiretamente a decisão do STF.

O terceiro caso para o qual chamamos atenção é relativo ao tema da união homoafetiva, que também traz importantes considerações sobre a formação de precedentes. Em fevereiro de 2008, o governador do Rio de Janeiro, Sérgio Cabral, apresentou uma ação pedindo ao STF para interpretar o Estatuto dos Servidores Públicos do Rio de Janeiro, na parte referente à concessão de pensões e licenças. Atualmente, esses benefícios são concedidos a cônjuges (casamento) e companheiros (união estável), mas o judiciário do Rio de Janeiro tem se pronunciado de maneira não homogênea quanto à extensão desses benefícios a casais homossexuais. O mero reconhecimento da "sociedade de fato", para fins patrimoniais - artifício jurídico já utilizado pelos tribunais em casos de união estável entre companheiros heterossexuais, quando não havia dispositivo protetor desse regime do Código Civil - e cuja aplicação a casais homossexuais está sendo feita por analogia em algumas sentenças - não é suficiente, pois o que está em jogo nesta demanda é o reconhecimento da relação de "afeto". O pedido é específico (interpretação do Estatuto e uniformização da jurisprudência do Rio de Janeiro) e tem público-alvo delimitado (servidores públicos do Rio de Janeiro), mas qual seria o impacto do reconhecimento da constitucionalidade da equiparação entre união estável e união homoafetiva pelo STF? Ele tem potencial para atingir os demais estados da federação, bem como casais homossexuais não servidores públicos, pois a decisão do STF teria efeitos erga omnes. Além disso, o caso não requer apenas a interpretação do Estatuto dos Servidores Públicos do Rio de Janeiro, mas também a do Código Civil (art. 1.723) e da própria Constituição, que estabelece que a união estável se dá entre homem e mulher (art. $226, \S 3^{\circ}$ ). Além disso, ao equiparar a união homoafetiva à união estável e reconhecer a existência de relação de afeto, a decisão do STF possibilitaria a aplicação, no 
futuro, de outras regras do direito de família a casais homossexuais, como adoção ou mesmo casamento, pois a união estável estaria a um passo da unidade familiar. Essa é uma decisão difícil, ainda não tomada pelo Tribunal, e que movimenta diversos grupos em torno de sua argumentação.

Há quem veja esse fenômeno, presente nos casos supracitados, como manifestação de um ativismo judicial ou de judicialização da política. Não vamos abordar esse ponto, mas nos parece que a atividade atualmente desempenhada pelo STF não é imprópria à função de um Tribunal, embora de fato incomode, especialmente aqueles que se atêm a leituras tradicionais e conceitos abstratos sobre separação dos poderes. O processo de legitimação da criação e aplicação do direito é bem mais complexo que o dos artifícios de argumentação. Compartilhamos, no entanto, o mesmo problema: a atuação do STF é legítima? O caminho de resposta é distinto e, no caso deste artigo, bastante pontual.

A fim de demonstrar e garantir um grau maior de legitimidade em sua atuação, percebe-se uma preocupação especial por parte dos ministros ao argumentarem nesses casos difíceis. Eles recorrem a pedidos de vista, proferem votos extensos, solicitam audiências públicas, aceitam a apresentação de amici curiae, realizam audiências informais com grupos interessados, concedem entrevistas antecipando seus posicionamentos etc. Há também uma grande cobertura da mídia sobre a atuação do STF - notícias de julgamentos são divulgadas em tempo real, os links para a íntegra dos votos são divulgados antes da publicação dos acórdãos, são realizadas matérias especiais sobre casos complexos, entrevistas com diferentes atores concernidos etc.

No entanto, falta algo - tanto em relação aos ministros como à "cobertura" do STF -, ou seja, falta uma observação mais detalhada sobre o seu processo decisório e as incongruências que pode acarretar neste papel mais "ativo" do Tribunal. Estudar o processo decisório do STF não é uma questão meramente formal. Compreender melhor como os ministros votam é fundamental para que se exerça um controle democrático mais apurado de suas decisões. A leitura minuciosa de casos difíceis mostra que a falta de clareza, coerência ou até a dificuldade de se encontrar a ratio decidendi (a linha argumentativa da decisão) são obstáculos a essa função. ${ }^{4}$

Um bom exemplo para introduzir esse campo de trabalho espinhoso é a já mencionada ação direta de inconstitucionalidade sobre pesquisas com célulastronco (ADI 3510). Após intensos debates promovidos pelos atores interessados, a ação foi considerada integralmente improcedente pelo Tribunal. A decisão final, que manteve, por seis votos a cinco, a permissão para realização desse tipo de pesquisa, contou com inúmeras divergências na argumentação dos ministros do STF. Um elemento que chama a atenção nos votos individuais desses cinco ministros que decidiram pela inconstitucionalidade das pesquisas é a inclusão de condições à interpretação de constitucionalidade da lei, o que eles denominaram "decisão aditiva”, uma nova possibilidade de atuação do STF como legislador positivo. 
Preocupados com que a efetivação das pesquisas fosse baseada em parâmetros éticos, os ministros condicionaram sua liberação à instituição de um órgão central de controle do uso de células-tronco, à adequação de alguns termos técnicos presentes no texto da lei, à inclusão de uma cláusula de subsidiariedade para o exercício das pesquisas, entre outras medidas. Cada ministro previu uma condição diferente, os votos não se comunicavam. Cada voto de caráter "aditivo" era computado pelo placar binário de votação como sendo pela inconstitucionalidade das pesquisas.

Essa forma de contabilização gerou polêmica. O ministro Cezar Peluso discordou da contabilização de seu voto como sendo pela inconstitucionalidade da lei, pois entendeu que a essência de seu voto (sua ratio decidendi) era favorável à realização das pesquisas. No placar, a maioria pendeu pela constitucionalidade da lei, pela permissão incondicionada das pesquisas. Mas e se fosse o contrário? E se os votos que estabelecem condições díspares entre si formassem um placar majoritário? A Lei de Biossegurança seria completamente inconstitucional? Se, ainda assim, essa lei pudesse ser considerada constitucional, qual a condição e de qual ministro teria de ser cumprida? De todos? Os ministros teriam de deliberar novamente sobre os termos das condições apresentadas? E, mais importante, no cenário de análise que propomos: como dotar a uma decisão do STF os amplos efeitos que o próprio Tribunal tem procurado dar às suas decisões se não for possível, em alguns casos, determinar qual é a decisão final? Como influenciar cortes inferiores se não é possível reconhecer qual é a decisão do STF? O STF tem dado uma resposta clara à sociedade quando decide sobre casos difíceis? Essas são questões que parecem não estar no horizonte de preocupações dos ministros do STF, embora representem obstáculos à legitimidade das decisões do Tribunal, especialmente se ele se impõe um papel mais "ativo".

Ocupar um papel político importante e dialogar com as demais instituições (Legislativo e Executivo) não é um equívoco em si. Disso não decorre uma ilegitimidade da atuação do STF. Contudo, esse novo cenário exige maior atenção sobre o processo decisório do Tribunal. Poderíamos traduzir essa polêmica para os termos empregados neste artigo. Os ministros estão diante de casos difíceis, em que há necessidade de decidir formando um precedente que sirva de parâmetro para a decisão de futuros casos. A argumentação é alvo de maior atenção, seja por parte dos próprios ministros, seja por parte da sociedade. Ainda assim, alguns aspectos importantes relacionados à coerência da decisão não são observados. Por exemplo, o que é ratio decidendi (linha argumentativa principal, que pode ser utilizada como precedente em casos futuros) e o que é obter dictum (opinião dos ministros expressa nos votos, a qual não produz efeitos na solução de casos futuros)? A ratio decidendi é do ministro ou do Tribunal? Em que medida o atual processo decisório do STF oferece entraves à legitimidade das decisões do Tribunal nesse novo contexto? 
A orientação dos ministros para a formação de precedentes, nas decisões de casos difíceis, parece ser uma tendência recente, que contrasta com o (não/mau) uso que os ministros tradicionalmente fazem de suas "decisões anteriores", citando-as de maneira aleatória, sem confirmação do conteúdo da decisão (ratio decidendi) -, ou de maneira estratégica -, apenas aquelas que favoreçam a linha argumentativa do ministro. Percebe-se que, em casos difíceis, é cobrado do STF um diálogo com as decisões anteriores, afinal os ministros são convocados a fixar um "novo" entendimento para a decidibilidade de casos futuros. No entanto, às vezes, fica-se com a impressão de que há interesse apenas em fixar o "novo", sem necessariamente remontar a jurisprudência do Tribunal de maneira adequada. Some-se a isso o fato de a jurisprudência constitucional não ser objeto de estudo sistemático por parte da academia. Não há, portanto, demanda por maior coerência do Tribunal.

Mais que atentar para o (não/mau) uso dos precedentes, parece necessário remontar as dificuldades da própria extração da linha argumentativa das decisões do Tribunal. Partindo da ideia de Dworkin de romance em cadeia, comparação feita pelo autor entre o processo de interpretação do direito e a literatura, fica-se com a impressão de que o segundo capítulo de um romance em cadeia, em que o autor interpreta o capítulo que recebeu para então escrever o seu, é sempre interrompido. O que pretendemos com isso é alertar para a necessidade de uma continuidade, no tempo, no processo decisório. A teoria de Dworkin é útil na medida em que demonstra a necessidade de diálogo entre decisões para que se forme um entendimento coerente por parte da corte. Esse processo não visa engessar o processo criativo do juiz, atentando para a necessidade de sempre recorrer a casos antigos para formar seu convencimento. Pelo contrário, ele aponta para o fato de que uma corte que dialoga com suas próprias decisões pode obter melhor qualidade nestas, o que pode implicar em um processo interpretativo mais consolidado no tempo.

Essa dificuldade decorre, em parte, do próprio processo decisório do STF. Neste artigo, pretendemos ilustrar essas dificuldades a partir de alguns casos. Os casos não foram selecionados pela sua relevância temática ou repercussão social; eles servem a fins metodológicos de demonstração de algumas possíveis interferências do processo decisório na coerência argumentativa do Tribunal. Esses aspectos são muito pouco estudados e discutidos.

Para além da discussão do STF como um ator político, é preciso atentar para seu funcionamento institucional, até mesmo para colocá-lo, também, sob crivo público. Caso contrário, o STF, no sentido oposto que parece indicar seu recente "ativismo" e flerte em ser um Tribunal constitucional, permanecerá um palco de disputas de solução de casos pontuais e de maneira ad hoc, com um possível controle social apenas sobre a dimensão material e fática do caso. 


\section{O DRAMA DA PÁGINA EM BRANCO. DESAFIOS DE PROCESSO DECISÓRIO NA FORMAÇÃo de ratio decidendi no Supremo Tribunal Federal}

\section{I VotAÇÃO UNÂNIME = ÚNICA RATIO DECIDENDI?}

O primeiro caso ${ }^{5}$ a despeito de ter tido votação final unânime, com a presença de nove dos onze ministros do STF, ${ }^{6}$ não chega a formar uma única ratio decidendi do Tribunal. Por essa razão, ele foi escolhido para ilustrar o processo decisório do STF.

O caso envolve a interpretação do direito à reunião e seus limites. Um decreto do governador do Distrito Federal, Brasília, ${ }^{7}$ proibiu a utilização de carros de som na Praça dos Três Poderes, local onde se encontram os prédios-sede dos três poderes do Estado brasileiro: o Congresso Nacional, o Palácio do Planalto e o próprio STF. A proibição, fundamentada no direito daqueles que exercem atividade laboral na praça e em seus arredores, terminaria por impedir o exercício do direito de reunião, previsto constitucionalmente. Por sua vez, o exercício do direito de reunião, tal como está disposto no texto constitucional, configura-se condicionado ao preenchimento de alguns requisitos, ou seja, seu exercício já encontra algumas limitações no próprio texto constitucional. ${ }^{8}$

O problema enfrentado pelo Tribunal se resumiria às seguintes questões: pode o direito de reunião ser restringido por elementos diversos daqueles presentes no dispositivo constitucional? Se sim, quais os limites de tal regulamentação?

Podemos dizer que todos os ministros identificam o mesmo problema a ser decidido, a possibilidade e os meios da restrição a um direito fundamental, como é o direito de reunião. Contudo, o reconhecimento de um mesmo problema não significa que todos seguirão a mesma linha de raciocínio e fundamentação das decisões individuais. Apesar de tratar-se de uma decisão final unânime, decretando a inconstitucionalidade do decreto, não se pode dizer que se trate de uma ratio decidendi única.

O voto do relator, Ministro Ricardo Lewandowski, contém os principais fundamentos apresentados na decisão para a determinação da inconstitucionalidade do decreto analisado. Afirma desde o início de seu voto que o direito de reunião se relaciona com outros dois direitos: liberdade de expressão e manifestação do pensamento.

A presença do direito de reunião nas constituições brasileiras prévias à Constituição de 1988 seria um demonstrativo da garantia de uma liberdade pública de caráter fundamental no capítulo dos direitos e garantias individuais. Ao fazer tal constatação, o ministro toma o cuidado de demonstrar como e em que medida o direito de reunião é e já foi previsto como garantia constitucional. Nesse sentido, afirma também que os limites e as condições para seu exercício estão previstos no texto constitucional, não fazendo parte das atribuições de um legislador infraconstitucional a inclusão de novas possibilidades de restrição. Em resumo, "reunir-se pacificamente", "sem armas", sob a condição de que "não frustrem outra reunião anteriormente convocada para o mesmo local" e dependendo do "prévio aviso à autoridade competente" 
seriam as únicas limitações possíveis a esse direito fundamental. Pode-se dizer que esse é um dos principais fundamentos de sua decisão.

Ao mesmo tempo em que apresenta essa fundamentação, mantém um posicionamento claro no sentido de afirmar que a liberdade de expressão não configura um direito absoluto. Além de generalizar o argumento, dizendo que nenhum direito é absoluto, uma vez que até mesmo os direitos havidos como fundamentais encontram limites implícitos e explícitos no texto das constituições. A possibilidade de limitação de direitos fundamentais, que aparece como premissa para o desenvolvimento do raciocínio do juiz em sua fundamentação, pode ser aqui identificada como um segundo fundamento essencial.

Ao apresentar um exemplo de caso semelhante, que serviria para a contraposição dos argumentos até então expostos, o ministro aventa a possibilidade de se fazer uma reunião na frente de um hospital, situação na qual se apresentaria uma hipótese de colisão entre direitos fundamentais, em que o direito dos pacientes à recuperação da saúde certamente prevaleceria sobre o direito de reunião. Em uma situação como essa, a restrição ao uso de carros, aparelhos e objetos sonoros mostrar-se-ia perfeitamente razoável, tratando-se, assim, de uma exceção à regra da impossibilidade de novas limitações por parte de um legislador infraconstitucional, indicada por ele no início de seu voto.

A analogia feita pelo ministro mostra-se essencial para a configuração da ratio decidendi de sua decisão, uma vez que afirma que a situação do hospital não guarda nenhuma semelhança com o caso em julgamento. Proibir a utilização de carros, aparelhos e objetos sonoros, nesse e em outros espaços públicos, os quais o decreto discrimina, inviabilizaria por completo a livre expressão do pensamento nas reuniões levadas a efeito nesses locais, porque as tornaria emudecidas, sem nenhuma eficácia para os propósitos pretendidos.

A potencialidade de se causar um prejuízo irreparável àqueles que estão nas imediações da manifestação próxima a um hospital é o que justificaria a proibição dessa manifestação. O prejuízo irreparável, portanto, seria a condição para a possibilidade de novas restrições ao texto constitucional. A inexistência de um prejuízo irreparável, no caso do Decreto do governador do DF, impede que as duas situações sejam tratadas da mesma maneira.

A ratio de seu voto poderia ser entendida da seguinte maneira: a Constituição Federal já prevê possibilidades de restrição ao direito de reunião, que só poderiam ser aumentadas caso a reunião ferisse irreparavelmente direitos alheios. O decreto é inconstitucional em virtude da finalidade a que se volta, que não justifica a criação de mais uma limitação além daquelas já existentes na constituição.

Após a manifestação do relator, tem-se a votação dos demais ministros, a qual não se limita à aceitação ou rejeição da decisão tomada pelo primeiro, mas, sim, à inclusão de novos argumentos à decisão tomada. Cada um dos ministros dá sua decisão, 
contrária ou de acordo, fundamentada com a decisão tomada pelo relator. A narração dos votos em sequência seguirá a ordem em que se deu no momento da votação, agrupando-se as manifestações em um mesmo sentido.

Um segundo grupo de argumentos encontra-se presente no voto do ministro Eros Grau, que também defere o pedido de inconstitucionalidade. Sua fundamentação é completamente diversa da apresentada pelo ministro relator. Esse ministro afirma que a inconstitucionalidade deve-se a uma questão formal, já que a regulamentação de um direito fundamental, ainda que possível, não poderia ter sido feita por meio de decreto, mas tão-somente por meio de lei. A inconstitucionalidade por questões formais faz com que a matéria a ser julgada torne-se prejudicada. O ministro não faz nenhuma afirmação com relação aos fundamentos apresentados pelo ministro relator.

O terceiro grupo de argumentos presentes na decisão do caso privilegia a proteção da liberdade de expressão em detrimento de eventuais prejuízos que reuniões em locais públicos poderiam causar. A relação existente entre o direito de reunião e as liberdades de expressão e livre manifestação das ideias deixaria clara a preponderância destes sobre eventuais prejuízos decorrentes do exercício desses direitos. $\mathrm{O}$ argumento, presente unicamente no voto do ministro Celso de Mello, não deixa expressa a possibilidade ou impossibilidade de uma restrição legislativa do direito de reunião. Apesar de identificar o mesmo problema dos demais ministros, a ratio decidendi desse voto não inclui as mesmas razões pelas quais o decreto foi julgado inconstitucional pelo relator.

Diversamente do que sustentou o voto do ministro relator, podemos identificar, no voto do ministro Gilmar Mendes, a afirmação de que a Constituição Federal não prevê, expressamente, nenhuma reserva legal ao direito de reunião. Ao questionar a eventualidade de esse fato significar a impossibilidade de novas restrições a esse direito, o ministro vai em direção contrária à da afirmação do ministro relator. Assim, a própria formulação do inciso XVI, quando diz "desde que não frustrem outra reunião anteriormente convocada para o mesmo local”, já sugere o problema de eventual colisão, típica entre direitos idênticos - dois grupos que querem se manifestar no mesmo lugar e na mesma hora - dada a possibilidade de conflito e necessidade de intervenção de polícia, "sendo apenas exigido aviso prévio à autoridade competente", tema que também pode demandar algum tipo de disciplina. ${ }^{9}$ Em resumo, novas regulamentações, que, no caso do ministro relator decorreriam somente de casos excepcionais, são, na visão do ministro Gilmar Mendes, inerentes à possibilidade de exercício do direito de reunião. Haveria, portanto, a presença de uma reserva legal implícita, autorizadora de novas restrições ao direito de reunião, independentemente de ser essa restrição um meio de se garantir a efetivação de outro direito fundamental (tal como afirmado pelo ministro relator).

Por fim, pode-se reconhecer a existência de um último grupo de argumentos, que configuraria uma quarta ratio decidendi do caso julgado. O Ministro Sepúlveda 
Pertence julga procedente o caso concreto, mas afirma que isso não significa uma manifestação a respeito da possibilidade de regulação de direitos fundamentais.

Note-se, dessa maneira, a dificuldade em se determinar, ainda que em um caso de decisão unânime, qual foi a decisão tomada pelo Tribunal como um todo. Ainda que se entenda que o voto do ministro relator, que guia a tomada de decisão dos demais ministros, tem um peso maior na fundamentação do caso, podendo-se entender que a partir dele seria possível extrair a ratio decidendi, não há como deixar de considerar o fato de que fundamentações conflitantes com o voto do ministro relator relativizam a adequação dessa ratio decidendi ao que foi efetivamente decidido pelo Tribunal. A unanimidade se dá tão-somente com relação ao dispositivo da decisão, o elemento questionado por meio da ADI, mas não se reflete no momento da justificação dessa solução dada pelo Tribunal.

Uma consequência dessa peculiaridade da decisão do STF, que decorre do modo como se dá a tomada de decisão, é o alto grau de personalismo dotado aos seus julgamentos. Poder-se-ia falar em ratio do ministro, em uma linha de pensamento desenvolvida por ele e, inclusive, em aplicação de precedentes individuais. Não há, especialmente nos casos que envolvem aplicação de princípios - como ficou explícito no caso analisado -, a possibilidade de extração de uma ratio coletiva, institucional.

\section{i.2 Afinal, Qual é o problema que estamos decidindo?}

O segundo caso envolve a aplicação da pena de racismo a Siegfried Ellwanger, um editor-autor de livros que nega a existência do holocausto contra judeus, ocorrido na $2^{a}$ Guerra Mundial. O caso Ellwanger, como ficou conhecido na literatura jurídica do País, chamou a atenção de acadêmicos e juristas e teve grande impacto na mídia durante seu longo julgamento - de dezembro de 2002 a setembro de 2003.

A tese sustentada pelo autor, na impetração de um recurso ao STF (HC 82.424), era composta por um simples argumento: o crime de racismo não havia se configurado, pois judeus não compõem uma raça. Com argumentação, o autor pretendia ver afastada a acusação de racismo, crime constitucionalmente imprescritível, e configurar sua conduta como discriminação - crime prescritível que, por decurso de prazo, já não seria mais aplicável.

Diante de tese tão controvertida, a atenção dada pelo Tribunal a esse julgamento foi grande. Em uma decisão de quase quinhentas páginas, os ministros se dividiram em grupos de argumentos e teses diferentes acerca da conceituação de racismo, da condição dos judeus no Brasil, na Europa, hoje e desde tempos passados, o papel da liberdade de expressão e manifestação do pensamento em sociedades democráticas, possíveis limitações a esse direito e formas de se avaliar a legitimidade das limitações, a efetividade de incitações e manifestações que se dão por meio de livros, entre outros temas, acrescentados à medida que cada ministro anunciava sua decisão individual. 
O que se nota também nesse caso é o reconhecimento da característica reativa da decisão individual de cada ministro, ou seja, os votos são proferidos a partir da interpretação do voto relator. A cada decisão proferida, percebe-se que o ministro está preocupado não só em dar uma resposta para o caso em julgamento, mas em rebater ou corroborar um ponto específico de uma das decisões proferidas anteriormente. Acontece que o que poderia ser entendido como diálogo entre os ministros acaba por tornar-se uma profusão de argumentos que em alguns momentos se ligam e em outros se chocam, pois cada ministro elege para si um problema diverso a ser respondido pelo Tribunal, apoiando-se em argumentações anteriores para expressar a sobreposição de uma questão à outra, coisa que não necessariamente se relaciona com a realidade do julgamento.

Assim, é possível dizer que, no caso Ellwanger, os ministros não chegam a um acordo sobre qual é o problema principal do caso que estão decidindo. Cada ministro desenvolve a sua própria linha argumentativa e de fundamentação para o problema que consideram como principal no caso concreto. Isso significa que, em um julgamento no qual os onze ministros proferiram decisões fundamentadas individualmente, não é possível dizer que uma única questão foi decidida, o que não é em si um problema. No entanto, se as decisões não tratam das mesmas questões, identificamos um problema na decisão dos ministros.

De maneira simplificada e esquemática, foi possível identificar três ordens de problemas decididos pelos ministros: (a) raça é conceito jurídico ou biológico? Pode ser aplicada a judeus?; (b) quais são as condutas que configuram o crime de racismo? Publicar um livro? Ter uma editora? Caso a conduta incriminadora seja a publicação de um livro, de que tipo - como um manifesto, incitação ao racismo, científico ou revisionista?; (c) a liberdade de expressão excepciona ou não a aplicação da lei de racismo? A partir de cada problema enfrentado pelos ministros, é possível identificar o desenvolvimento de linhas de argumentação diferentes, que serão apresentadas a seguir.

Os ministros podem ser agrupados em quatro tipos diferentes de argumentos, que combinam esses problemas de formas diferentes, conforme foram apresentados pelos próprios ministros, como as questões centrais a serem respondidas pelo Tribunal:

(a.1) A primeira questão se resume à identificação ou construção de um conceito de racismo, problema central na visão dos ministros Cezar Peluso e Sepúlveda Pertence.

(a.2) Um segundo grupo de ministros questiona a possibilidade de haver crime de racismo contra judeus. Esse grupo é formado pelos votos dos ministros Moreira Alves, Celso de Mello, Carlos Velloso, Nelson Jobim e Ellen Gracie.

(b) Em terceiro lugar, quais seriam os meios pelos quais o crime de racismo pode ser cometido. É a questão essencial presente nos votos dos ministros Gilmar Mendes, Nelson Jobim e Carlos Velloso. ${ }^{10}$ 
(c) Por fim, qual seria o resultado do choque entre liberdade de expressão e dignidade da pessoa humana no caso da criminalização de manifestações do pensamento, é o centro do questionamento feito pelos ministros Carlos Britto e Marco Aurélio. ${ }^{11}$

Ao comparar essa divisão de "grupos de problemas" com a resposta construída por cada um dos ministros, percebe-se que não necessariamente todos os ministros se manifestam a respeito de todos os problemas existentes. Reconhecemos que casos difíceis são fonte de inúmeras questões jurídicas que, por vezes, ensejam leituras diferentes com relação aos problemas envolvidos pelo caso. ${ }^{12} \mathrm{O}$ que se identifica no julgamento do caso Ellwanger, porém, é a escolha, por parte de cada ministro, de um problema específico que, no dizer de cada um, resume a controvérsia como um todo. No limite, ao escolherem problemas diferentes, ao invés de terem perspectivas de interpretação diferentes de um mesmo problema, cada ministro decide um caso completamente diferente.

Inicialmente, pode-se dizer que há um consenso em relação a uma questão central do caso julgado. Todos os ministros, com exceção do relator - ministro Moreira Alves -, concordam com a premissa de que a discriminação contra judeus configura crime de racismo, já que esse conceito não se limita a um conceito biológico de raça. A conceituação jurídica de racismo, portanto, é elemento comum das decisões dos ministros, inclusive daqueles que decidem o caso em sentido contrário ao que se deu na decisão da maioria. Esse poderia ser identificado como um dos elementos constitutivos da ratio decidendi, que congregaria o entendimento de todos os onze ministros. No entanto, tal consenso é insuficiente para o que consideramos como ratio decidendi e sua relação com a potencialidade de normatização de um precedente. Entender que somente as premissas mais abstratas de um raciocínio formam a ratio decidendi de um caso é torná-lo quase inútil para a resolução de casos futuros. ${ }^{13}$

Com isso, queremos apontar que da aceitação unânime da premissa de que o conceito de raça se deve a fatores culturais, e não biológicos, não decorre a conclusão de que todos enxergam uma mesma questão jurídica a ser decidida pelo STF. O processo decisório, como é estruturado, permite tal escolha dos ministros, sobre qual problema querem resolver com sua argumentação, sem que haja um pronunciamento de todos os ministros sobre ele. Ao mesmo tempo, necessariamente, não há deliberação entre os ministros, para que cheguem a um acordo pelo menos com relação a qual é o principal problema trazido pelo caso.

\section{I.3 O QUE FOI DECIDIDO MESMO?}

O terceiro caso selecionado aborda a aplicação do Código de Defesa do Consumidor (CDC) às relações contratuais bancárias. ${ }^{14}$ Após o acórdão ser proferido pelo Tribunal, houve embargo de declaração ao conteúdo da ementa (resumo do julgamento), pois 
não estava claro se o seu conteúdo refletia realmente o que havia sido decidido pelos ministros e pelo Tribunal no acórdão. ${ }^{15}$ Durante a discussão do embargo, os ministros discordaram do conteúdo da ementa, pois ela correspondia apenas à linha argumentativa do voto do ministro relator, e não ao que havia sido deliberado por todos. Uma boa ementa deveria se aproximar, portanto, do conteúdo da ratio decidendi do Tribunal, e não da ratio decidendi de apenas um dos ministros, no caso o relator, responsável pela redação da ementa. O que se percebe, a partir da leitura da transcrição dos debates dessa audiência sobre o embargo, é que os ministros aproveitaram a ocasião para re-decidir o caso, apresentando argumentos diversos dos que haviam sido apresentados anteriormente (muitas vezes desconsiderando a ratio decidendi de seus votos na decisão anterior) e buscando uma nova ratio decidendi do Tribunal, fruto de um debate consensual sobre os termos que deveriam constar na ementa final do caso.

A discussão gira em torno da revisão da correção monetária e dos juros estipulados em contratos entre pessoas físicas ou pequenas empresas e instituições financeiras, em face da alegação de práticas abusivas por parte das últimas no estabelecimento das taxas de juros aplicáveis sobre as obrigações contratuais. As instituições financeiras questionavam a aplicação do Código de Defesa do Consumidor $^{16}$ a relações dessa ordem, pois o Sistema Financeiro teria peculiaridades e disciplina própria que afastariam o regramento do CDC. Assim sendo, a Confederação Nacional do Sistema Financeiro (Consif) propôs ação direta de inconstitucionalidade pretendendo a declaração da inconstitucionalidade da expressão "inclusive as de natureza bancária, financeira, de crédito e securitária”, constante do art. $3^{\circ}, \S 2^{\circ}$, da Lei n. 8.078/90.

A principal questão trazida pelo caso, e implícita na argumentação da Consif, diz respeito à definição sobre quem é competente para regular o Sistema Financeiro, essencialmente no que concerne à questão dos juros. ${ }^{17}$ Se a aplicação do CDC afetasse relações próprias ao Sistema Financeiro Nacional (art. 192 da Constituição Federal), estaria invadindo o âmbito reservado à disciplina por lei complementar.

O primeiro problema durante o julgamento foi a dificuldade das diferentes partes em concordarem quanto a qual seria a questão principal em debate. O ministro Joaquim Barbosa, em seu voto, explicita esse fato ao mostrar qual acha ser a questão de fundo: "A corte discutiu, desde o início do julgamento, se seria necessário utilizar da técnica de interpretação conforme a Constituição, julgando a ação parcialmente procedente, para estabelecer que o Código de Defesa do Consumidor não poderia ser aplicado em questões que discutissem juros".

A segunda questão decorre dos embargos à ata do julgamento. A ata é redigida pelo ministro relator Eros Grau e é embargada sob a alegação de não refletir a decisão do julgamento. A embargante alega contradição entre a certidão de julgamento (que afirma a improcedência total do pedido) e a ementa (que afirma a procedência parcial da ação). 
Durante as discussões do julgamento dos embargos ocorrem novas contradições. O ministro relator Eros Grau diz entender que todos concordaram quanto a um ponto, porem é contestado por colegas ${ }^{18}$. O ministro relator entende que a ratio decidendi explicitada em seu voto é unânime entre os ministros. No entanto, durante os debates, o entendimento do ministro é questionado e as rationes dos demais são consideradas. Os ministros, então, rediscutem o caso e uma nova ementa é elaborada, dessa vez reflexo do (novo) julgamento. ${ }^{19}$

Consideremos alguns problemas no julgamento. Primeiro, a dificuldade dos próprios ministros em identificar qual é a questão em discussão. Cada ministro decide sobre um ponto e não há a formação de rationes acerca do mesmo problema. Segundo, o ministro relator não consegue identificar quais foram as rationes de seus colegas e, portanto, não consegue identificar qual foi a ratio decidendi do julgamento, considerando somente a sua como prevalecente. Desse modo, não é possível a formação de uma ratio decidendi do Tribunal.

Como vimos, o grau de discricionariedade do relator, no momento de redigir a ementa do caso, é muito grande. Nesse caso, se não fossem opostos embargos de declaração à ementa, ela permaneceria não refletindo o julgamento.

Para se atingir um consenso, os ministros realizam um debate durante o julgamento da ementa em que se busca um denominador comum dos votos. Verifica-se, nesse momento, que eles fazem um novo julgamento, desconsiderando seus votos anteriores e, portanto, mudando sua ratio decidendi. ${ }^{20}$ No momento em que os ministros reveem suas decisões e as discutem, pode-se dizer que há uma busca por uma ratio decidendi do Tribunal. A decisão unânime pela improcedência da ação demonstra que há um entendimento coletivo da corte.

O desfecho do julgamento deixou claro que não há, no STF, um consenso sobre qual entidade deve regular os juros no Brasil e que há limites para a aplicação do CDC a instituições financeiras. A decisão é incapaz de sinalizar como se dá a incidência do CDC sobre relações financeiras, o que resultará em novos conflitos no momento da consideração dessa decisão em casos futuros. Segundo o ministro Marco Aurélio, esses limites não estão claros, sendo deixados à definição por meio de processos subjetivos que sejam iniciados no Poder Judiciário. O julgamento da questão é, portanto, jogado para o futuro e o Tribunal ganha tempo para formar seu entendimento ou, no caso em questão, talvez fique clara a intenção deste de evitar se pronunciar sobre tema polêmico e formar um precedente. ${ }^{21}$

A partir dos casos analisados, pode-se notar que há diversas relações entre a estrutura da argumentação dos ministros e do Tribunal e o processo decisório do STF: uma votação unânime não possui, necessariamente, uma ratio decidendi do Tribunal sobre o caso, pois ela pode versar apenas sobre a parte dispositiva; cada ministro pode, no limite, estabelecer uma ratio decidendi própria em seu voto independente; por vezes, os ministros diferem não apenas na linha argumentativa em torno de um mesmo problema 
que o caso trás, mas, também, com relação ao próprio problema a ser solucionado no caso. Não há um espaço determinado no processo decisório para que os ministros decidam de maneira consensual sobre o problema envolvido pelo caso ou sobre qual linha de argumentação deve prevalecer no Tribunal; o processo de argumentação é eminentemente individual; o voto do relator é importante na determinação dos votos seguintes, mas, em casos difíceis ou de grande repercussão, os ministros procuram desenvolver uma argumentação própria. Os próprios ministros têm dificuldade em extrair a ratio decidendi do Tribunal ou mesmo de cada voto em um determinado acórdão; a ementa de um caso não necessariamente representa a ratio decidendi do Tribunal sobre o caso, ela pode ser uma leitura do ministro relator sobre o que foi decidido.

\section{ESBOÇANDO O SEGUNDO CAPÍTULO DO ROMANCE. QUANDO ALGO JÁ FOI DITO ANTES}

O último caso ilustra o esforço dos ministros do STF em remontar os precedentes do Tribunal para fixarem um novo entendimento. O diálogo com as decisões anteriores do Tribunal parece ter sido crucial no caso, pois havia um entendimento anterior consolidado na sua jurisprudência. Inovar implicava justificar muito bem o que estava mudando e por quê. A ruptura com um precedente claro exige maior argumentação, obriga o Tribunal a dialogar com a sua história. Mas será que os ministros estão fixando um novo entendimento quando constroem diferentes rationes? Em outras palavras, eles concordam com o passado, mas divergem com relação à regulamentação futura. Isso é ruim?

O problema comum identificado pelos ministros é a constitucionalidade da prisão do depositário infiel, uma vez que a Constituição Federal de 1988 permite e a Convenção Americana de Direitos Humanos proíbe tal prisão. Várias ações que tramitam atualmente no STF abordam essa questão. Em três delas, os ministros fixaram o entendimento da inconstitucionalidade da prisão do depositário infiel. ${ }^{22}$ Os argumentos dos ministros, no entanto, diferem com relação à interpretação de por que tal prisão é inconstitucional. ${ }^{23}$

Há um entendimento claramente consolidado na jurisprudência do STF de que tratados internacionais são equiparados hierarquicamente à legislação infraconstitucional. Tratados de direitos humanos, no entanto, ocupariam uma posição hierárquica diferenciada? $\mathrm{O}$ art. $5^{\circ}, \S 2^{\circ}$, da Constituição Federal abria margem à interpretação sobre a recepção como normas constitucionais dos tratados de direitos humanos: "Os direitos e garantias expressos nesta Constituição não excluem outros decorrentes do regime e dos princípios por ela adotados, ou dos tratados internacionais em que a República Federativa do Brasil seja parte”.

A análise da íntegra dos votos dos ministros Celso de Mello e Gilmar Mendes permite estudar como cada ministro retomou o histórico da jurisprudência do Tribunal e, no caso de Celso de Mello, o seu próprio entendimento anterior sobre o 
tema. Os ministros dialogaram com os precedentes contrários da corte ou com a ratio decidendi de seus votos anteriores, formando um novo entendimento. ${ }^{24}$

Os ministros não buscam apenas a solução do caso concreto, mas também estabelecer parâmetros para a decidibilidade de conflitos futuros, que envolvam a interpretação da hierarquia jurídica de todos os tratados internacionais de direitos humanos firmados pelo Brasil. O ministro Gilmar Mendes adota a tese da supralegalidade dos tratados internacionais de direitos humanos, pois estariam entre Constituição e a legislação ordinária, ${ }^{25}$ e identifica que essa tese já havia sido aventada em caso anterior pelo ministro Sepúlveda Pertence. ${ }^{26}$

O ministro Celso de Mello, por sua vez, adota a tese da constitucionalidade dos tratados internacionais de direitos humanos e revê seu entendimento anterior, de que tinham nível hierárquico de legislação ordinária. Para ele, a principal motivação para a formação de uma nova ratio decidendi é a emenda constitucional que estabeleceu a regra para que os tratados internacionais de direitos humanos que venham a ser assinados pelo País tenham status constitucional condicionado à aprovação por três quintos do Congresso Nacional. ${ }^{27} \mathrm{~A}$ dúvida permanece para os tratados internacionais de direitos humanos que foram internalizados antes da emenda constitucional que estabelece essa regra. Este é o caso da Convenção Americana de Direitos Humanos. Para Celso de Mello, nestes casos, os tratados já haviam sido incorporados pela Constituição Federal. ${ }^{28}$ Já para Gilmar Mendes, nestes casos, os tratados dependem de votação pelo Congresso Nacional para que alcem a condição de constitucionais. ${ }^{29}$

A partir do material levantado, podemos identificar, portanto, duas linhas argumentativas acerca da constitucionalidade da prisão do depositário infiel: (a) a prisão é inconstitucional em decorrência da supralegalidade da Convenção Americana de Direitos Humanos; (b) a prisão é inconstitucional em decorrência da constitucionalidade da Convenção Americana. Com o julgamento conjunto das três ações, foi possível contrastar o posicionamento dos ministros do STF acerca de qual tese eram adeptos. Formou-se um placar de cinco contra quatro no Tribunal pela supralegalidade dos tratados internacionais de direitos humanos. ${ }^{30}$

Cabem, no entanto, algumas considerações sobre o interregno em que a maioria do Tribunal já havia se pronunciado pela proibição da prisão do depositário infiel, mas que ainda pairava a dúvida sobre qual seria o posicionamento do Tribunal sobre a posição hierárquica dos tratados internacionais de direitos humanos. Ou seja, o período em que os votos majoritários pela proibição já geravam efeitos para algumas decisões do próprio Tribunal, mas que a posição hierárquica dos tratados internacionais só gerava polêmicas.

Entendemos que a particularidade do processo decisório do STF permite que os ministros apresentem diferentes rationes em seus votos, sem que necessariamente elas componham uma configuração majoritária que possa ser compreendida como uma ratio decidendi do Tribunal sobre o caso. Isso implica, em nossa opinião, uma decisão 
diferida no tempo. Os atuais ministros jogam a decisão sobre qual é a ratio decidendi que prevalecerá para o futuro, para outros tribunais e juízes. As diferentes rationes produzidas são elementos persuasivos para a argumentação de futuras decisões. Essa forma de votação possibilita um entendimento a ser formado ao longo do tempo.

A falta de clareza de uma decisão (quando não se consegue extrair uma ratio decidendi do Tribunal ou do voto), por vezes, constitui uma maneira de decidir de maneira informal, evitando formar um precedente do Tribunal que provoque consequências indesejáveis em casos de grande repercussão; a pluralidade de rationes, por vezes, joga para o tempo futuro a decisão sobre qual linha argumentativa deve prevalecer.

Em cortes supremas de outros países, também está presente a questão da coerência no tempo, embora haja uma diferença clara. Nessas cortes, o que possibilita na decisão uma mudança de entendimento futura ou a formação de uma nova ratio decidendi é o voto dissidente ou concorrente, em contraposição à ratio decidendi do Tribunal, que se encontra no acórdão único. Tais votos têm o potencial de se tornarem rationes de decisões futuras. Funcionam como orientações da própria corte de outras possíveis formas de decidir o mesmo caso e fundamentá-lo. No caso do STF, por não haver um texto único de seus acórdãos e, sim, uma sucessão de votos, é possível que a decisão de um caso produza múltiplas rationes, que poderão influenciar a decisão de casos futuros. $\mathrm{O}$ desenho institucional do STF favorece, em nossa opinião, a formação de ratio decidendi de cada ministro, e não da corte, mas isso não necessariamente é algo ruim.

\section{Potencial democrático do Processo decisório do Supremo Tribunal Federal e de uma cultura de Precedentes NO SISTEMA JURÍDICO BRASILEIRO}

A particularidade do processo decisório do STF não implica necessariamente em um deficit de legitimidade. Podemos especular um potencial democrático do mesmo em determinados casos. Quando a decisão é composta por múltiplas rationes, isso pode indicar que diferentes argumentos foram representados por ela. Argumentos que talvez tenham sido levantados na esfera pública, por meio do debate promovido pelo trâmite do caso no STF. ${ }^{31}$

Há potencial democrático também quando a decisão sobre a ratio prevalecente é jogada para uma construção futura, pois isso possibilita a inclusão de novos atores no processo decisório. ${ }^{32}$ Não apenas os próprios ministros, mas outros juízes, advogados e a própria sociedade, podem influenciar na escolha da ratio decidendi prevalecente. Isso pode ser particularmente relevante em casos de alto impacto social ou com bastante repercussão na mídia, possibilitando ampla participação na construção da argumentação e interpretação dos ministros e do STF.

Essa potencialidade só seria factível na medida em que houvesse uma cultura de respeito aos precedentes no sistema jurídico brasileiro. De nada serve identificar que 
há um ponto de interpretação em disputa - em que falta uma ratio decidendi prevalecente -, buscar participar e influenciar a formação desta ratio, se não houver depois um reconhecimento pelos demais tribunais de que aquela decisão serve como precedente.

Com isso, não queremos dizer que esta decisão será estritamente vinculante, mas, sim, que seria um elemento persuasivo importante na argumentação dos demais juízes, com o qual teriam de dialogar, interpretar criativamente e, eventualmente, se afastar de maneira justificada, formando um novo entendimento.

Segundo Dworkin, o autor envolvido na elaboração de um romance em cadeia deve considerar a continuidade do romance, e não um novo começo a cada capítulo. Ao detalhar o processo de interpretação, há duas dimensões às quais sua interpretação será submetida à prova. A primeira é a da adequação, em que o intérprete não pode adotar uma interpretação que acredite representar sua leitura individual da obra - à qual nenhum outro autor poderia chegar - fugindo à própria figura de um romancista em cadeia, preocupado com uma interpretação que faça o texto fluir como um todo. A segunda dimensão é a escolha entre as interpretações adequadas daquela que se ajusta melhor à obra em desenvolvimento como um todo. ${ }^{33}$ Essas dimensões devem ser levadas em consideração pelo(s) autor(es) em todas as etapas da obra, do primeiro ao último capítulo do romance.

Em um sistema jurídico em que há respeito aos precedentes, pode-se identificar um processo contínuo de julgamento, um romance em cadeia. As decisões a partir de um contexto histórico não são dadas de maneira pontual apenas para se resolver um único caso concreto. São consideradas no tempo. Também por isso é que buscamos uma definição mais ampla de precedentes, como sendo o diálogo fundamentado com decisões anteriores.

A própria participação reiterada nesse processo de disputa entre interpretações possíveis pode acarretar uma cultura de respeito aos precedentes. À medida que diferentes atores enxergarem o STF como um fórum de disputa de interpretações, em que direitos são potencialmente criados ou reconhecidos, e utilizarem as decisões obtidas em outros fóruns, pode-se criar uma cultura de precedentes no sistema jurídico brasileiro. Quando esses outros atores identificarem um ponto positivo na ratio decidendi formada, poderão constituir um elemento de controle social sobre a interpretação e aplicação desta ratio em casos futuros. Identificamos, portanto, um potencial democrático, que é o controle social sobre o processo de interpretação e aplicação do STF, na medida em que haja uma cultura de respeito aos precedentes.

Em resumo, com decisões claras, nas quais se pode extrair a ratio decidendi, seja do voto, seja do Tribunal, há maior transparência, accountability, e melhor diálogo com a sociedade. ${ }^{34} \mathrm{O}$ ganho com uma cultura de respeito aos precedentes em que está presente a noção de romance em cadeia, por sua vez, é a possibilidade de um controle social, uma incidência estratégica de longo prazo, sobre os precedentes formados pelo Tribunal. 
Este artigo, não conclui que, necessariamente, o processo decisório do STF implica a falta de uma cultura de precedentes. Tampouco a reforma do regulamento do Tribunal, transformando o processo decisório em uma esfera de deliberação e consenso entre os ministros seria a única solução para a instauração dessa cultura de precedentes.

Sem dúvida, publicizar o processo pelo qual os ministros decidem pode provocar uma discussão pública sobre o procedimento, sobre a instituição, e não apenas sobre os casos concretos. Abrir essa margem de deliberação pública sobre o desenho do Tribunal é importante, até mesmo para que todas essas transformações institucionais pelas quais o STF tem passado recentemente - que tendem a uma concentração de poderes e a um “ativismo político" - não sejam fruto apenas de onze ministros, e não passem em brancas nuvens, sem controle social.

Podemos, inclusive, especular potencialidades democráticas na forma atual em que o Tribunal está estruturado, mas isso depende de uma mudança na cultura jurídica, rumo a um respeito maior aos precedentes do STF e maior controle social sobre como o STF decide.

: ARTIGO APROVADO (15/06/2009) : RECEBIDO EM 03/04/2009

\section{NOTAS}

1 Agradecemos os comentários e críticas apresentados a uma versão preliminar deste artigo pelos professores Diogo R. Coutinho e Virgílio Afonso da Silva, ambos da Faculdade de Direito da Universidade de São Paulo, e ao Grupo Extramuros da Sociedade Brasileira de Direito Público, no qual foram gestadas inúmeras reflexões aqui presentes e pudemos discutir uma versão preliminar deste texto. Agradecemos, ainda, aos integrantes do Núcleo Direito e Democracia do Centro Brasileiro de Análises e Planejamento (Cebrap) e do grupo de trabalho "Controles democráticos e instituições políticas" do $32^{\circ}$ Encontro Anual da Associação Nacional de Pós-Graduação e Pesquisa em Ciências Sociais (Anpocs), em especial a Rogério Bastos Arantes e Adrián Gurza Lavalle. Agradecemos a Ben-Hur Belmonte Neto pela revisão e pelas sugestões. As eventuais incorreções são de inteira responsabilidade das autoras.

2 Número que toma por base os dados divulgados pelo próprio STF em seu site. Por ano, em média, o STF tem decidido em torno de cem mil casos. Disponível em: <http://www.stf.jus.br/portal/cms/verTexto.asp?servico=estatistica\&pagina $=$ movimentoProcessual $>$.

3 O mesmo tipo de inclusão se deu na decisão envolvendo a reserva indígena Raposa Serra do Sol (PET 3.388). Dessa vez as condições impostas pelos ministros (dezenove ao todo) fazem parte da decisão final majoritária.

4 Utilizaremos ao longo deste artigo um conceito amplo de ratio decidendi, definição dada por MacCormick: "[Ratio decidendi] is a ruling expressly or implicitly given by a judge which is sufficient to settle a point of law put in issue by the parties' argument in a case, being a point in which a ruling was necessary to his justification (or one of the alternative justifications) of the decision of the case". MacCORMICK, Neil; SUMMERS, Robert S. Eds. Interpreting Precedents. Aldershot: Dartmouth, 1997. 
5 ADI n. 1.969

6 Apesar de nove ministros terem votado na ADI n. 1.969, apenas sete apresentaram fundamentações próprias. A análise dos argumentos a seguir faz-se com referência a esses sete votos. Consideramos que a fundamentação dos votos das ministras Ellen Gracie e Carmen Lúcia segue integralmente o voto do relator.

7 Decreto n. 20.098 de 15/03/1999.

8 Artigo $5^{\circ}$, XVI, da Constituição Federal: "XVI - todos podem reunir-se pacificamente, sem armas, em locais abertos ao público, independentemente de autorização, desde que não frustrem outra reunião anteriormente convocada para o mesmo local, sendo apenas exigido prévio aviso à autoridade competente”.

9 Ao que parece, ele admite a possibilidade de regulamentação dos elementos já presentes no inciso. A questão é saber se o legislador pode criar novas limitações. Isso não fica claro, pois ele acaba fundamentando seu voto pelo voto do relator, que admite restrições desde que não desproporcionais.

10 Os ministros Nelson Jobim e Carlos Velloso encontram-se nos dois grupos. Isso porque a interpretação acerca de qual seria o problema central identificado em cada voto depende do modo como esses problemas são apresentados pelos próprios ministros. Nos dois casos comentados neste artigo, os ministros afirmam, em momentos diferentes, que essas são as duas questões centrais a serem enfrentadas pelo STF.

11 Como se pode observar, o agrupamento dos ministros não reflete uma uniformidade no tipo de resposta dada ao caso em julgamento. Aqueles que identificam o mesmo problema não votam, necessariamente, em um mesmo sentido, assim como os que têm a mesma decisão final não identificaram, necessariamente, problemas semelhantes.

12 Essa pluralidade de leituras pode até ser considerada reflexo do influxo de diferentes demandas de interpretação e construção de conceitos por parte da esfera pública no processo decisório do STF, o que seria algo positivo em termos de legitimidade democrática das decisões do Tribunal. Sobre o caso Ellwanger: "O que se presenciou, naquelas longas sessões de julgamento, foi, diante da abertura de um campo de indeterminação no Direito, a disputa pela fixação do sentido e do alcance de uma norma, a concorrência de diversos argumentos dogmaticamente aceitáveis e as diversas possibilidades de interpretação de um mesmo dispositivo legal que, muito provavelmente, expressavam opiniões que circulavam na esfera pública. Evidentemente, para traçar o caminho desses argumentos da sociedade até o Poder Judiciário, seria preciso realizar pesquisas empíricas”. Rodriguez, Püschel e Machado, mimeo, 2006.

13 Aqui, podemos identificar dois tipos de influências que um precedente pode gerar em decisões futuras. Rationes muito abstratas, que se resumem, por exemplo, a afirmar a preponderância de um princípio jurídico em relação a outro, em um determinado tipo de situação, pode ser considerada uma ratio abrangente, pois terá a capacidade de influenciar um grande número de casos futuros. Rationes mais específicas, que se referem mais precisamente a determinados tipos de situações, e acabam por exigir diversas condicionantes para que possa ser aplicada em casos futuros. No entanto, o grau de persuasão, ou de força normativa, que cada uma dessas rationes terá será inverso ao seu grau de amplitude. Ou seja, uma ratio genérica, ampla, tem a capacidade de servir de parâmetro de julgamento de um número maior de casos, mas, ao mesmo tempo, seu poder de persuasão com relação a esses casos será mais fraco, e mais facilmente se justifica a sua não aplicação.

14 A ação direta de inconstitucionalidade 2591-ED/DF foi julgada improcedente pelos ministros pela maioria de nove votos a dois.

15 Os embargos servem para esclarecer algum ponto da decisão considerado obscuro, contraditório, omisso ou duvidoso. No caso em questão, se pretendia somente que o acórdão do julgamento ficasse mais claro, não que o julgamento fosse modificado. No entanto, a decisão dos embargos de declaração foi unânime pela improcedência total da ação direta de inconstitucionalidade, em contraposição à ementa redigida pelo ministro relator Eros Grau, pela procedência parcial da ação.

16 O Código de Defesa do Consumidor (Lei n. 8.078/90) visa reequilibrar interesses nas relações contratuais, de modo a evitar que a posição menos favorecida do consumidor, em comparação aos fornecedores ou prestadores de serviços que com ele contratam, resultasse em abuso por parte destes em detrimento dos consumidores. A Súmula 297 do Superior Tribunal de Justiça de 12/05/2004 reconheceu aplicação do CDC a instituições financeiras. 


\section{2 : ESCREVENDO UM ROMANCE, PRIMEIRO CAPÍTULO: PRECEDENTES E PROCESSO DECISÓRIO NO STF}

17 Transparece essa preocupação na petição inicial, notadamente no instante em que ataca a inadequação do $\mathrm{CDC}$ às relações que ocorrem no Sistema Financeiro, pois o $\mathrm{CDC}$, em seu art. 51, permite a revisão judicial de um contrato quando este se torne excessivamente oneroso ao devedor, entretanto, sem garantir, conforme faz o Código Civil, o equilíbrio das prestações entre as partes. A caracterização desse tópico, como o cerne do debate, também pode ser encontrada no Parecer do Procurador-Geral da República, que opinou pelo provimento parcial da ação.

18 Eros Grau considera que todos os ministros concordam com a exceção à aplicação do CDC por ele preconizada, ao passo que nenhum dos ministros evidenciou efetivamente essa posição: "Evoluo no sentido de acolher, porque chegamos ao mesmo resultado, mas, talvez, de modo mais efetivo"; "Julgo improcedente. Chegamos com isso a um consenso; mais uma vez o colegiado manifesta sua sabedoria e prudência"; "Nem mesmo a circunstância de meu voto original ter sido redesenhado no correr da sessão de julgamento ensejaria qualquer dúvida" (grifos no original). No entanto, o ministro é confrontado pelo colega Sepúlveda Pertence: "A unanimidade vai do inciso III da ementa até a declaração expletiva de que o preceito vinculado no art. $3, \S 2$, do CDC deve ser interpretado em coerência com a constituição. A partir daí há uma dispersão de fundamentos entre os votos proferidos".

19 “A nova ementa será aquela consubstanciadora da síntese do julgamento de hoje”, ministro Celso de Mello.

20 O ministro Eros Grau, por exemplo, que havia votado pela procedência parcial da ação, vota pela total improcedência da mesma. O julgamento da Adin teve o placar de nove votos a dois, ao passo que os embargos foram julgados em decisão unânime pela total improcedência da ação sem interpretação conforme a constituição.

21 Trata-se de uma estratégia informal de decisão do STF, para os casos em que uma decisão final de mérito, especialmente sobre controle concentrado de constitucionalidade, que geraria efeitos erga omnes, e poderia provocar amplas consequências políticas ou econômicas negativas. Isso viabiliza decisões finais de mérito sem que essa decisão acarretasse graves inconvenientes. Outra estratégia informal de decisão seria o adiamento de decisões finais de mérito, até que se consume ou se acomode uma situação de fato, que faça a ação perder seu objeto. Como essa estratégia informal leva, via de regra, ao arquivamento da ação, ela permite ao STF resolver casos difíceis sem criar precedentes que comprometeriam a coerência da ordem jurídica e da jurisprudência do Tribunal (ROCHA, 2004).

22 As decisões ocorridas em uma mesma sessão plenária $(03 / 12 / 2008)$ ainda não foram publicadas integralmente no site do STF (RE 349703, RE 466343 e HC 87585). Mesmo antes da decisão final, o posicionamento apresentado pela maioria dos ministros nesses casos já era utilizado como precedente da corte. Essa maioria justificou a concessão de liberdade em sede de habeas corpus pelo STF em vários casos. Nesse período, a maioria representou uma ratio decidendi em formação do Tribunal e produziu efeitos, mesmo sem a ação ter sido finalizada, servindo como um "precedente" para outras decisões do tribunal.

23 A análise será feita com base na íntegra de dois votos, já publicados, dos ministros Celso de Mello e Gilmar Mendes. Não tivemos acesso a todos os votos proferidos, mas decidimos manter a análise dos casos, pois esses votos são ilustrativos da formação de rationes diversas entre os ministros, e da possibilidade de jogar para o tempo futuro qual delas prevalecerá. Informações adicionais serão fornecidas com base em notícias disponíveis no próprio STF e em sites especializados em informação jurídica.

24 O ministro Celso de Mello, em casos anteriores, considerava que: “A prisão civil não transgride a Constituição, nem ofende o sistema de proteção instituído pela Convenção Americana sobre Direitos Humanos (Pacto de San José da Costa Rica, de 1969)". "A convenção ou tratado internacional que se oponha ou restrinja o conteúdo de aplicação da lei ou altere lei fundamental é considerado inválido” (Habeas corpus 81319). (Notícia STF. "Pleno reitera entendimento de que depositário infiel será preso quando não pagar dívida”, 07/02/2002).

25 "Entendo que, desde a ratificação, pelo Brasil, sem qualquer reserva, do Pacto Internacional dos Direitos Civis e Políticos (art. 11) e da Convenção Americana sobre Direitos Humanos - Pacto de San José da Costa Rica (art. $\left.7^{\circ}, 7\right)$, ambos no ano de 1992, não há mais base legal para prisão civil do depositário infiel, pois o caráter especial desses diplomas internacionais sobre direitos humanos lhes reserva lugar específico no ordenamento jurídico, estando abaixo da Constituição, porém acima da legislação interna. O status normativo supralegal dos tratados internacionais de direitos humanos subscritos pelo Brasil, dessa forma, torna inaplicável a legislação infraconstitucional com ele conflitante, seja ela anterior ou posterior ao ato de ratificação" (voto ministro Gilmar Mendes - RE $n$. $466.343 /$ SP). 
26 Gilmar Mendes reconheceu uma ratio decidendi vencida do ministro Sepúlveda Pertence, "essa tese foi aventada, em sessão de 29/03/2000, no julgamento do RHC n. 79.785-RJ, pelo voto do Eminente Relator, Min. Sepúlveda Pertence, que acenou com a possibilidade da consideração dos tratados sobre direitos humanos como documentos supralegais" (voto ministro Gilmar Mendes - RE n. 466.343/SP).

27 “É que, como já referido, a superveniência, em dezembro de 2004, da EC n. 45 introduziu um dado juridicamente relevante, apto a viabilizar a reelaboração, por esta Suprema Corte, de sua visão em torno da posição jurídica que os tratados e convenções internacionais sobre direitos humanos assumem no plano do ordenamento positivo doméstico do Brasil. Vale dizer, essa nova percepção crítica, legitimada pelo advento da EC n.. 45/2004 - que introduziu um novo paradigma no cenário nacional - estimula novas reflexões, por parte do STF, em torno das relações da ordem jurídica interna brasileira com o direito internacional em matéria de direitos humanos" (voto ministro Celso de Mello - Habeas corpus 87.585-8 TO).

28 "É preciso ressalvar, no entanto, como precedentemente já enfatizado, as convenções internacionais de direitos humanos celebradas antes do advento da EC n. 45/2004, pois, quanto a elas, incide o $\$ 2^{\circ}$ do art. $5^{\circ}$ da Constituição, que lhes confere natureza materialmente constitucional, promovendo sua integração e fazendo com que se subsumam à noção mesma de bloco de constitucionalidade" (voto ministro Celso de Mello - Habeas corpus 87.585-8 TO).

29 "De qualquer forma, o legislador constitucional não fica impedido de submeter o Pacto Internacional dos Direitos Civis e Políticos e a Convenção Americana sobre Direitos Humanos - Pacto de San José da Costa Rica, além de outros tratados de direitos humanos, ao procedimento especial de aprovação previsto no art. $5^{\circ}, \S 3^{\circ}$, da Constituição, tal como definido pela EC n. 45/2004, conferindo-lhes status de emenda constitucional" (voto ministro Gilmar Mendes - RE n. $466.343 / \mathrm{SP})$

30 De acordo com notícia publicada pelo STF, à tese da supralegalidade, defendida pelo ministro Gilmar Mendes, aderiram os ministros Marco Aurélio, Ricardo Lewandowski, Cármen Lúcia e Menezes Direito, e à tese da constitucionalidade dos tratados internacionais de direitos humanos do ministro Celso de Mello, os ministros Cezar Peluso, Eros Grau e Ellen Gracie. Notícia STF. "STF restringe a prisão civil por dívida a inadimplente de pensão alimentícia, 03/12/2008. O placar da do STF, especificamente com relação a este tema, portanto, foi de cinco contra quatro.

31 Os argumentos plurais presentes na decisão do STF podem ser decorrentes inclusive da participação direta de diferentes atores no próprio processo decisório. Alguns mecanismos de participação estão previstos em ações de controle concentrado de constitucionalidade, como os amici curiae e as audiências públicas. Os atores que se valem desses mecanismos procuram influenciar a ratio decidendi prevalecente do tribunal naquele caso. O objetivo dessa participação é a formação de precedentes para casos futuros, como em casos de grande impacto social ou repercussão na mídia, como os que atualmente tramitam no STF sobre o uso de células-tronco para pesquisas científicas e sobre as cotas para negros, indígenas e pobres nas universidades.

32 Não podemos ignorar, no entanto, que em muitos casos, a decisão é jogada para o futuro como uma maneira do tribunal não participar da decisão do conflito, justamente para não formar um precedente (ROCHA, 2004).

33 Dworkin, 2003, p. 277-278.

34 "Todo depende de la concepción de sentencia que escojamos como la más interesante y convincente. Una concepción de sentencia que denomino formalista propendería por la expedición de sentencias aptas para la solución exclusiva de los litigios, para hacer 'justicia en el caso concreto'. Una sentencia formalista entonces no consideraría significativos valores como la coherencia, la claridad y la buena citación. Por el contrario, una sentencia que se rija por una concepción axiológica superará la egoísta función de resolución de litigios particulares. Una sentencia antiformalista o axiológica, también se preocupa porque su escritura conduzca a una comprensión clara de todos os argumentos, tendrá un hilo conductor al mejor estilo de los dramas modernos, provocará la sensación de que se lee algo más que el derecho esotérico de los especialistas y estructura responderá a criterios de coherencia, claridad y eficacia del lenguaje. Así el final de la sentencia, es decir la solución del caso, será una consecuencia lógica del nudo y el clímax expuestos en las motivaciones de los jueces. La jurisprudencia así, quizá se convierta en un invaluable repositorio de experiencia normativa" (Lopez Medina e Gordillo, 2002, p. 45-46). 
044 : ESCREVENDO UM ROMANCE, PRIMEIRO CAPÍTULO: PRECEDENTES E PROCESSO DECISÓRIO NO STF REFERÊNCIAS BIBLIOGRÁFICAS

DWORKIN, Ronald. Law as interpretation. Texas Law Review, v. 60, p. 527-550, 1982. O império do Direito. São Paulo: Martins Fontes, 2003.

LÓPEZ MEDINA, Diego Eduardo; GORDILLO, Roberto. (2002) Consideraciones ulteriores sobre el análisis estático de jurisprudencia. Revista de Derecho Público, n. 15, p. 3-47.

ROCHA, Jean Paul Cabral Veiga da. A capacidade normativa de conjuntura no Direito Econômico: o déficit democrático da regulação financeira. São Paulo, USP, 2004. Tese de doutoramento à Faculdade de Direito da Universidade de São Paulo.

RODRIGUEZ, José Rodrigo; PÜSCHEL, Flavia Portella; MACHADO, Marta Rodriguez de Assis. O raciocínio jurídico-dogmático e suas relações com o funcionamento do Poder Judiciário e a democracia. Texto apresentado no $3^{\circ}$ Congresso Latino Americano de Ciência Política promovido pela Associação Latino-Americana de Ciência Política (Alacip), Campinas, Brasil, 2006.

STONE, Julius. The ratio of the ratio decidendi. The Modern Law Review, v. 22, n.6, p. 597-620, 1959.

VERÍSSIMO, Marcos Paulo. A constituição de 1988, vinte anos depois: suprema corte e ativismo judicial "à brasileira”. Revista Direito GV, v. 4, n. 2, p. 407-440, 2008.

Adriana de Moraes Vojvodic Rua Leôncio de Carvalho, 306, $7^{\circ}$ andar
Paraíso - 04003-010
São Paulo - SP - Brasil
adri.moraisagmail.com

Rua Rocha, 220, cj. 23 Bela Vista - 01330-000 São Paulo - SP - Brasil

ana.machadolafgv.br

Rua Leôncio de Carvalho, 306, $7^{\circ}$ andar Paraíso - 04003-010 São Paulo - SP - Brasil evorahl2lagmail.com
Mestranda em Direito do Estado pela Faculdade de Direito da Universidade de São Paulo (FDUSP)

Bolsista da Fundação de Amparo à Pesquisa do Estado de Säo Paulo (Fapesp)

Pesquisadora da Sociedade Brasileira de Direito PÚBLICO (SBDP)

\section{Ana Mara França Machado}

Mestranda em Filosofia e Teoria Geral do Direito pela Faculdade de Direito da Universidade de São Paulo (FDUSP)

$$
\text { Pesquisadora da Escola de Direito da }
$$

FundaÇÃo GETULIO VARGAS (DIREITO GV)

\section{Evorah Lusci Costa Cardoso}

Mestre e doutoranda em Filosofia e Teoria Geral do Direito PELA FACULDADE dE DIREITO DA Universidade de São Paulo (FDUSP)

Membro do Núcleo de Direito e Democracia do Centro Brasileiro de Análises e Planejamento (Cebrap)

Coordenadora da Escola de Formação da Sociedade BRASILEIRA DE DIREITO Público (SBDP) 